\title{
The Effects of Meditation on Perceived Stress and Related Indices of Psychological Status and Sympathetic Activation in Persons with Alzheimer's Disease and Their Caregivers: A Pilot Study
}

\author{
K. E. Innes, ${ }^{1,2}$ T. K. Selfe, ${ }^{1,2}$ C. J. Brown, ${ }^{2}$ K. M. Rose, ${ }^{2,3}$ and A. Thompson-Heisterman ${ }^{3}$ \\ ${ }^{1}$ Department of Community Medicine, West Virginia University School of Medicine, P.O. Box 9190, Morgantown, \\ WV 26506-9190, USA \\ ${ }^{2}$ Center for the Study of Complementary and Alternative Therapies, University of Virginia Health System, P.O. Box 800782, \\ McLeod Hall, Charlottesville, VA 22908-0782, USA \\ ${ }^{3}$ Department: Family, Community \& Mental Health Systems, School of Nursing, University of Virginia Health System, \\ Charlottesville, VA 22908-0782, USA
}

Correspondence should be addressed to K. E. Innes, kinnes@hsc.wvu.edu

Received 8 November 2011; Revised 5 December 2011; Accepted 5 December 2011

Academic Editor: David Mischoulon

Copyright ( $) 2012$ K. E. Innes et al. This is an open access article distributed under the Creative Commons Attribution License, which permits unrestricted use, distribution, and reproduction in any medium, provided the original work is properly cited.

Objective. To investigate the effects of an 8-week meditation program on perceived stress, sleep, mood, and related outcomes in adults with cognitive impairment and their caregivers. Methods. Community-dwelling adults with a diagnosis of mild cognitive impairment or early-stage Alzheimer's disease, together with their live-in caregivers, were enrolled in the study. After a brief training, participants were asked to meditate for 11 minutes, twice daily for 8 weeks. Major outcomes included measures of perceived stress (Perceived Stress Scale), sleep (General Sleep Disturbance Scale), mood (Profile of Mood States), memory functioning (Memory Functioning Questionnaire), and blood pressure. Participants were assessed pre- and post-intervention. Results. Ten participants ( 5 of 6 dyads) completed the study. Treatment effects did not vary by participant status; analyses were thus pooled across participants. Adherence was good (meditation sessions completed/week: $X=11.4 \pm 1.1$ ). Participants demonstrated improvement in all major outcomes, including perceived stress $(P<0.001)$, mood (overall, $P=0.07$; depression, $P=0.01$ ), sleep $(P<0.04)$, retrospective memory function $(P=0.04)$, and blood pressure (systolic, $P=0.004$; diastolic, $P=0.065)$. Conclusions. Findings of this exploratory trial suggest that an 8-week meditation program may offer an acceptable and effective intervention for reducing perceived stress and improving certain domains of sleep, mood, and memory in adults with cognitive impairment and their caregivers.

\section{Introduction}

Alzheimer's disease (AD), the most common form of dementia, is a chronic, progressive brain disorder resulting in a loss of memory, reasoning, language skills, and the ability to care for one's self $[1] . \mathrm{AD}$ is the seventh leading cause of death in the US [2], affecting 5.3 million Americans at an estimated cost of $\$ 148$ billion, figures that are expected to increase dramatically in the coming years $[3,4]$. AD affects quality of life for both the patient and the caregiver in profound ways. Many individuals with cognitive impairment become unable to engage in once loved activities that gave them a sense of purpose or pleasure [5]. Behavioral and social skills may also deteriorate, resulting in feelings of social isolation, anxiety, and depression, which, in turn, further increase risk for poor mental and physical health outcomes $[6,7]$. For example, neuropsychiatric symptoms are common in adults with $\mathrm{AD}$, as well as in those with mild cognitive impairment (MCI) $[8,9]$. Up to $64 \%$ of $\mathrm{AD}$ patients [10] and $59 \%$ of those with mild cognitive impairment [11] suffer from sleep disruptions, and depressive symptoms are common in both $\mathrm{AD}$ and MCI sufferers, affecting up to $87 \%$ and $83 \%$ of these populations, respectively $[12,13]$. 
Caregivers are also at elevated risk for distressful symptoms, including increases in sleep disturbances, depressive symptoms, and burden, as well as cognitive decline relative to age and gender-controlled noncaregivers [14, 15]. For example, studies in community-dwelling caregivers of persons with dementia have prevalence rates of self-reported sleep disturbances and depression of up to $68 \%$ and $55 \%$, respectively $[16,17]$, as well as a six-fold increased risk of dementia compared to noncaregivers [18]. Likewise, recent research has shown caregivers of MCI patients to suffer significantly elevated burden [19] and mood disturbance [20], and to have a need for increased support services that is comparable to those caring for dementia patients [21]. Distressful feelings, impaired sleep, and subsequent maladaptive behaviors in caregivers have been associated with further deterioration of the care recipient's functional and psychological status, culminating in further distress in the caregiver [17, 22, 23]. Distressful sleep and mood responses of both members of the caregiving dyad can thus contribute to a vicious cycle that may lead to deleterious health effects for both, and, ultimately, to institutionalization of the care recipient $[6,17,24,25]$.

There is an obvious need to identify prevention and management strategies that target the complex effects of chronic stress and address the associated multiple, interrelated mental, and physical health challenges affecting these vulnerable caregiver dyads. Of particular promise in this regard is meditation, an ancient psychophysical discipline that is gaining increasing favor throughout the western industrialized world as a means of reducing stress and improving mental and physical well-being [26].

As indicated in recent systematic reviews by our group and other investigators, and by the growing body of original research on the health effects of meditation, there is mounting evidence that even brief ( 5 days -8 weeks) meditation programs may improve neuropsychological, metabolic, and clinical profiles in a range of populations [26-30]. For example, studies have shown meditation to reduce perceived stress $[28,31-33]$, anxiety $[28,31,33]$, and depressive symptoms [33-35], enhance quality of life $[30,34]$, decrease sleep disturbance [32], improve several domains of cognition [35], reduce sympathetic activation, and enhance cardiovagal tone both acutely and long term in clinical as well as nonclinical populations $[27,36]$.

While research in Alzheimer's patients and their caregivers remains limited, findings from previous observational studies and a recent small clinical trial suggest that meditation practice may reduce stress, anxiety, and depression and improve health and cognitive outcomes in both adults with cognitive impairment and their caregivers [31, 37-39]. However, no studies to date have examined the effects of a structured meditation program in caregiver dyads. To our knowledge, the current pilot study is the first trial to investigate the effects of meditation on perceived stress and related indices of psychological morbidity and sympathetic activation in caregiver dyads, and among the first to investigate the effects of meditation in caregivers or $\mathrm{AD}$ patients.

\section{Methods}

2.1. Study Participants. Community-dwelling caregiving dyads were recruited using newspaper ads, flyers, and brochures placed in medical offices (e.g., the UVA Memory Disorders Clinic) and other public places in Charlottesville, VA, USA. Study advertisements detailed the study and eligibility requirements and provided study contact information for those interested in participating. Eligible participants were caregiving dyads composed of: (1) an adult with a physicianconfirmed diagnosis of MCI or early stage AD of at least 6week duration, and current examination within the last 12 months with a score of 20 or higher on the Mini Mental State Exam (MMSE); and (2) a live-in caregiving relative (both members of the caregiving dyad were required to enroll in the study); 18-100 years of age, English-speaking, and willing and able to complete paper-and-pencil questionnaires and abide by the protocol. Reasons for exclusion included: mid or late stage dementia; history of schizophrenia or psychosis; pregnant or caring for an infant; primary caregiver for a second person not in this study; began or stopped taking a cholinesterase inhibitor (e.g., donepezil (Aricept)) or psychotropic medication (e.g., antipsychotic and antianxiety agents) within the previous 6 weeks; serious physical trauma or diagnosis of serious chronic health condition requiring medical treatment and monitoring within the previous 3 months (e.g., diabetes, serious renal disease, and cancer); acute coronary syndrome or cerebrovascular event within the past 6 months (e.g., myocardial infarction, and coronary artery bypass); and meditation practice within the past 12 months. All participants provided informed consent, and the study was approved by the University of Virginia Institutional Review Board.

2.2. Outcome Measures. Assessment of perceived stress and related physiologic and psychological profiles was performed twice during the study: at baseline and following the 8-week treatment period. The baseline assessment was performed immediately following provision by the participant of written informed consent to participate in the study. The followup assessment was performed upon each participant dyad's completion of the 8 -week meditation program. At each visit, heart rate and blood pressure, measures of sympathetic activation, were measured three times, and the average was recorded using an automated blood pressure monitor (Omron Model HEM-780) following a 5-minute seated rest period. Each participant also completed a short battery of established, well-validated, and self-report instruments to assess perceived stress (Perceived Stress Scale [PSS]) [40], mood and affect (Profile of Mood States [POMS]) [41], Positive and Negative Affect Scale [PANAS]) [42], stress hardiness (Dispositional Resilience Scale [DRS]) [43], sleep quality (General Sleep Disturbance Scale [GSDS]) [44], selfcompassion (Self-Compassion Scale [SCS]) [45], and cognitive status (Memory Functioning Questionnaire [MFQ]) [46]. In addition, participants were administered a brief treatment expectancy questionnaire, as well as a short exit questionnaire adapted from that used in our previous studies regarding the effects of yoga on gait in the elderly [47] 
and cardiovascular disease (CVD) risk in older adults. This survey includes both structured and open-ended questions regarding the participants' experience with the study staff, perceived benefits and problems with the meditation intervention, reasons for leaving the study early or not adhering to the study protocol, and other concerns. Specific questions regarding perceived measurement burden were included. Participants completed the exit questionnaire at the followup assessment or (for those not completing the study), at another time of the participant's choosing. In addition, participants recorded the number of minutes of meditation practiced each day for the 8 weeks of the study using a daily meditation log.

\subsection{Intervention. Immediately following baseline assess-} ment, participants received 30-45 minutes of in-person meditation training. Participants were taught the Kirtan Kriya, a basic, easy-to-learn form of yogic meditation that incorporates both a mental component (repetition of the Sa-Ta-NaMa mantra) and a physical/motor component (touching the thumb to each fingertip in sequence with the mantra). For this study, we used the 11-minute version of the practice (repeating the mantra for: 2 minutes aloud, followed by 2 minutes whispering, 3 minutes silently, 2 minutes whispering again, and ending with 2 minutes aloud). Participants were given a meditation $\mathrm{CD}$ and an illustrated instruction sheet for home use. The meditation CD contained four tracks: the first track comprised an 11-minute guided meditation session which participants were instructed to follow at least once a week to reinforce the in-person training; the second track was identical to track one but accompanied by ocean sounds; the third track provided only the timing cues needed for the participants to conduct the meditation session without guidance; track four also provided only timing cues, but coupled with ocean sounds. Participants were instructed to meditate for 11 minutes twice a day, every day for 8 weeks (for a total of 112 sessions) and to record each practice session on the daily meditation log.

2.4. Statistical Analysis. Descriptive statistics were generated for the baseline characteristics of each group: cognitively impaired patients and caregivers. Potential differences between characteristics of caregivers and cognitively impaired participants were evaluated using chi square (for categorical variables), independent student's $t$-tests (for continuous variables with a normal distribution), or Wilcoxon signed rank (pre-post) tests (for ordinal variables or continuous variables with evidence of skewing). We used separate repeated measures ANOVA models (multivariate tests) to assess the effects of meditation on change over time (baseline to 8 weeks) in perceived stress and in related indices of psychological and physiological health. Because this was a small exploratory pilot study, and we were looking for trends as well as significant differences, all statistical tests were evaluated using an alpha of 0.05 (two-tailed test).

\section{Results}

Twelve adults ( 6 dyads), ranging in age from 48 to 85 years $(X=73.3 \pm 3.9$ years), enrolled in the study (Table 1$)$. Seven participants were female ( 3 caregivers and 4 cognitively impaired), and 5 were male ( 3 caregivers and 2 cognitively impaired). All participants were married; five of the six caregivers were spouses. One participant with cognitive impairment was cared for by her daughter. Ten participants were retired, one (caregiver) was a homemaker, and one (caregiver) was employed full time. Ninety-two percent of participants were college educated, with 58\% reporting a Bachelor's degree or higher level of education. All participants were non-Hispanic white. Poor sleep quality and/or daytime sleepiness/fatigue at least 2 times per week was reported by more than $90 \%$ of participants. Caregivers reported significantly poorer sleep $(P<0.01)$ and demonstrated significantly higher memory function $(P=0.01)$ at baseline than did participants with cognitive impairment but were similar in other baseline characteristics (Table 1).

Ten participants ( 5 dyads) completed the study, including 6 women and 4 men; one dyad withdrew in the first 2 weeks due to scheduling conflicts. Compliance was very good overall, with participants completing an average of $11.4 \pm 1.1$ meditation sessions per week (out of 14 possible). Because treatment effects did not vary by participant status (cognitively impaired versus caregiver), the two groups were pooled for the purposes of analysis. As illustrated in Table 2, participants demonstrated statistically significant improvement in the primary outcome measure, perceived stress $(P=0.03)$ as well as in sleep quality $(P=0.02)$, retrospective memory function $(P=0.04)$, and systolic blood pressure $(P=0.004)$ following the 8-week intervention. Participants also demonstrated significant or marginally significant reductions in diastolic blood pressure $(P=0.065)$ and mood impairment as measured by the POMS (overall, $P=0.07$; depression, $P=0.01$; anger/hostility, $P=0.09$ ). Adjustment for treatment expectancy did not alter these findings. Reduction in perceived stress was correlated with positive changes in total $\operatorname{mood}(r=0.83$ and $P=0.003)$ and sleep scores $(r=0.57$ and $P=0.08$ ). Similarly, improvement in sleep was strongly correlated with improvements in $\operatorname{mood}(r=0.71$ and $P=$ 0.03 ), again suggesting strong inter-relationships among these factors. No statistically significant improvements in positive or negative affect (as measured by the PANAS) were noted (Table 2). In addition, participants did not show significant changes in either stress hardiness or self-compassion, suggesting that the observed improvements in stress, sleep, and mood were not mediated by these factors.

Participant feedback regarding the study and the meditation program was positive overall. Responses to structured and open-ended questions on exit questionnaires and comments on meditation logs indicated generally high satisfaction with the program, with 9 of the 10 participants who completed the exit questionnaire indicating that they enjoyed the meditation and the quiet time to relax and/or reflect. Concerns regarding the program included scheduling the time to meditate, with nine participants commenting that they had some difficulty with the time factor. One caregiver 
TABLE 1: Baseline characteristics of participants with MCI/early stage Alzheimer's disease and their caregivers $(N=6$ dyads).

\begin{tabular}{|c|c|c|c|c|c|}
\hline & \multicolumn{2}{|c|}{ Cognitively impaired $(N=6)$} & \multicolumn{2}{|c|}{ Caregivers $(N=6)$} & \multirow{2}{*}{$P$} \\
\hline & Mean/N & SE/percent & Mean $/ N$ & SE/percent & \\
\hline \multicolumn{6}{|l|}{ Demographic factors } \\
\hline Age (mean \pm SE in years) & 75.00 & 3.65 & 71.50 & 5.25 & NS \\
\hline Gender & & & & & NS \\
\hline Male & 2 & $33.33 \%$ & 3 & $50.00 \%$ & \\
\hline Female & 4 & $66.67 \%$ & 3 & $50.00 \%$ & \\
\hline Education & & & & & NS \\
\hline At least 4 years of college & 4 & $66.67 \%$ & 3 & $50.00 \%$ & \\
\hline Less than 4 years of college & 2 & $33.33 \%$ & 3 & $50.00 \%$ & \\
\hline Married & 6 & $100.00 \%$ & 6 & $100.00 \%$ & \\
\hline Occupation & & & & & NS \\
\hline Retired & 5 & $83.33 \%$ & 5 & $83.33 \%$ & \\
\hline Homemaker & 1 & $16.67 \%$ & 0 & $0.00 \%$ & \\
\hline Employed & 0 & $0.00 \%$ & 1 & $16.67 \%$ & \\
\hline \multicolumn{6}{|l|}{ Mood, stress, and sleep quality } \\
\hline Perceived stress scale & 17.33 & 2.95 & 17.33 & 2.20 & NS \\
\hline \multicolumn{6}{|l|}{ Profile of mood states (POMS) } \\
\hline Total & 17.50 & 8.37 & 18.17 & 7.60 & NS \\
\hline Tension/anxiety & 4.33 & 2.11 & 6.33 & 1.61 & NS \\
\hline Confusion & 6.67 & 1.28 & 3.17 & 1.78 & NS \\
\hline Depression & 9.50 & 3.08 & 7.83 & 2.56 & NS \\
\hline Anger/hostility & 7.67 & 2.19 & 7.00 & 1.24 & NS \\
\hline Vigor & 17.33 & 2.16 & 16.17 & 1.58 & NS \\
\hline Fatigue & 6.67 & 1.78 & 10.00 & 0.97 & NS \\
\hline \multicolumn{6}{|l|}{ Positive-negative affect scale } \\
\hline Negative affect & 15.33 & 1.67 & 15.33 & 1.56 & NS \\
\hline Positive affect & 33.50 & 2.53 & 34.00 & 2.57 & NS \\
\hline General sleep disturbance scale (Total) & 19.33 & 3.73 & 49.83 & 7.05 & 0.003 \\
\hline Memory functioning scale (Total) & 230.67 & 6.78 & 304.50 & 13.73 & 0.001 \\
\hline \multicolumn{6}{|l|}{ Measures related to sympathetic activation } \\
\hline Heart rate (average) & 65.67 & 3.68 & 63.83 & 5.48 & NS \\
\hline Systolic blood pressure (average) & 129.83 & 9.02 & 132.83 & 6.33 & NS \\
\hline Diastolic blood pressure (average) & 72.17 & 5.80 & 78.00 & 3.06 & NS \\
\hline
\end{tabular}

NS: $P>0.10$.

reported difficulty concentrating (but appreciated his wife's dedication and the obvious help it has been to her), and another caregiver stated that the cognitively impaired member of the dyad found the practice challenging.

\section{Discussion}

Findings of this preliminary pilot study suggest that a meditation program is feasible to implement in adults with cognitive impairment and their caregivers, and may offer a costeffective intervention for improving perceived stress, mood, sleep, and blood pressure in this population. To our knowledge this is the first study to assess the effects of a mindbody program in caregiver-cognitively impaired dyads, and among the first to evaluate the effects of a simple meditation program in community-dwelling adults with cognitive impairment. Our findings are consistent with those of a recent study in 14 adults with memory loss that showed improved well-being and neuropsychological function over time, along with increased cerebral blood flow after a similar, 8-week, 12-minute/day Kirtan Kriya meditation program $[39,48]$. In contrast to our findings, a recent controlled study of mindfulness meditation in caregivers of dementia patients did not show significant improvements over time in caregiver-perceived stress, mood, or sleep [49], possibly in part due to reduced compliance [4]. Studies regarding the effects of more complex mindfulness-based meditation programs in caregivers have also shown significant attenuation of most benefits over time $[50,51]$, perhaps in part due to the higher 
TABLE 2: Change over time in indices of psychosocial status, sleep, memory functioning, and sympathetic activation in adults with cognitive impairment and their caregivers $(N=10$ participants).

\begin{tabular}{|c|c|c|c|}
\hline & $\begin{array}{c}\text { Baseline } \\
(\text { Mean } \pm \text { SE })\end{array}$ & $\begin{array}{c}\text { Posttreatment } \\
(\text { Mean } \pm \text { SE })\end{array}$ & $P^{*}$ \\
\hline \multicolumn{4}{|l|}{ Mood, stress and sleep quality } \\
\hline Perceived stress scale & $17.3 \pm 2.1$ & $11.8 \pm 1.4$ & 0.03 \\
\hline \multicolumn{4}{|l|}{ General sleep disturbance scale } \\
\hline Total & $32.9 \pm 5.8$ & $26.9 \pm 3.8$ & 0.02 \\
\hline Daytime fatigue & $7.1 \pm 1.7$ & $4.9 \pm 0.7$ & 0.04 \\
\hline Daytime alertness & $15.3 \pm 1.8$ & $14.4 \pm 1.6$ & NS \\
\hline Sleep duration & $8.6 \pm 2.1$ & $5.8 \pm 1.9$ & 0.04 \\
\hline Sleep medication & $5.7 \pm 1.9$ & $5.2 \pm 1.8$ & NS \\
\hline \multicolumn{4}{|l|}{ Profile of mood states } \\
\hline Total & $17.9 \pm 6.5$ & $9.7 \pm 4.1$ & 0.07 \\
\hline Tension/anxiety & $5.4 \pm 1.5$ & $4.7 \pm 1.7$ & NS \\
\hline Confusion & $5.3 \pm 1.4$ & $4.5 \pm 1.2$ & NS \\
\hline Depression & $9.4 \pm 2.2$ & $5.7 \pm 1.2$ & 0.01 \\
\hline Anger/hostility & $7.2 \pm 1.4$ & $6.0 \pm 1.4$ & 0.09 \\
\hline Vigor & $16.8 \pm 1.4$ & $18.1 \pm 1.7$ & NS \\
\hline Fatigue & $7.4 \pm 1.1$ & $6.9 \pm 0.9$ & NS \\
\hline \multicolumn{4}{|l|}{ Memory functioning scale } \\
\hline Total & $255.1 \pm 13.9$ & $252.0 \pm 12.2$ & NS \\
\hline Frequency forgetfulness & $140.1 \pm 10.1$ & $134.4 \pm 8.2$ & NS \\
\hline Seriousness of forgetting & $78.9 \pm 5.9$ & $75.4 \pm 5.8$ & NS \\
\hline Retrospective memory functioning & $10.8 \pm 1.8$ & $17.1 \pm 2.5$ & 0.04 \\
\hline Mnemonic & $25.4 \pm 3.0$ & $25.1 \pm 1.9$ & NS \\
\hline \multicolumn{4}{|l|}{ Measures related to sympathetic activation } \\
\hline Heart rate (average) & $64.0 \pm 1.5$ & $63.8 \pm 1.6$ & NS \\
\hline Systolic blood pressure (average) & $128.2 \pm 4.0$ & $121.8 \pm 4.0$ & 0.004 \\
\hline Diastolic blood pressure (average) & $74.1 \pm 1.9$ & $69.4 \pm 2.0$ & 0.07 \\
\hline
\end{tabular}

${ }^{*}$ Repeated measures ANOVA.

NS: $P \geq 0.10$.

time demands of the intervention. A simpler meditation program such as that implemented in this study may carry advantages in terms of sustainability, especially in already heavily burdened populations such as caregivers. While it is unknown if the benefits observed in our study persisted, the high compliance and generally high satisfaction expressed by participants are encouraging. Based on participant comments, compliance and continued practice might be further improved by emphasizing flexible practice times to accommodate different or changing schedules.

Identifying feasible, cost-effective interventions for reducing stress and for improving sleep and mood in both cognitively impaired adults and their caregivers is of clear importance, given the high prevalence and negative impact of chronic stress, sleep disturbance, and mood impairment in these populations. For example, the chronic stress that often characterizes the lives of family caregivers has been linked to adverse changes in sleep [17], mood [52, 53], and immunological function $[52,54]$ and elevated risk for metabolic syndrome, CVD, and mortality $[55,56]$ in this population.
Chronic psychological stress can have profound effects on memory and behaviors in persons both with and without cognitive impairment and has been prospectively linked to increased risk for dementia in older adults [57]. Elevations in hypothalamic pituitary adrenal (HPA) axis activity, manifested by elevated cortisol levels, are associated with hippocampal volume loss and memory impairment in nondemented, elderly persons $[58,59]$. Further, in mouse models for Alzheimer's disease, studies show elevated production of $\beta$-amyloid under stressful conditions, suggesting that stress may contribute to an increase in plaque deposits and progression in $\mathrm{AD}[60]$.

Similarly, prevalence of mood disorders is high in both $\mathrm{AD}$ patients and their caregivers. For example, depressive symptoms are estimated to affect up to $87 \%$ and $55 \%$, respectively, of these populations $[12,16]$. Depressive symptoms and other distressful states have, in turn, been linked to significantly increased risk for diabetes, CVD, stroke [61], and other components of the metabolic syndrome $[62,63]$ and are a significant contributor to the profound reductions 
in quality of life reported by those with cognitive impairment and their family caregivers $[12,64]$. In addition, mood disturbance can contribute to impairment of both sleep and memory, as well as to HPA axis dysregulation and autonomic dysfunction and related proinflammatory changes; in this way, poor emotional health may promote a vicious cycle of adverse physiologic, neuroendocrine, and psychosocial changes that foster the development and progression of CVD, AD, and related chronic conditions $[59,65,66]$.

Sleep disruption, also common in cognitively impaired adults and their caregivers, likewise has negative effects on health, functioning, and quality of life in both patients and their carers and is a major reason for institutionalization $[11,24,25]$. Sleep disturbances have been strongly associated, in a bidirectional manner, with depression and other distressful states [67], autonomic dysfunction [68, 69], and can promote glucose intolerance, proinflammatory changes, dyslipidemia, obesity, and hypertension $[68,70,71]$. Sleep disturbances have likewise been linked with increased risk for both for incident type 2 diabetes and for CVD morbidity and mortality [59, 70-72]. The association of sleep to chronic illness and related risk factors appears strongly reciprocal [70, 73].

The reductions in blood pressure observed in this study are consistent with previous research regarding the effects of simple meditation programs in older adults with hypertension, coronary artery disease, and related chronic conditions $[36,74,75]$. Caregivers are at greater risk for hypertension [76], and recent research has suggested that elevated blood pressure may largely explain the increased coronary heart disease risk observed in this population [77]. Elevated blood pressure has also been linked to subsequent cognitive decline and implicated in the initiation and progression of $\mathrm{AD}$ [7880].

Thus, if our findings are confirmed in larger randomized controlled trials, a simple and inexpensive intervention, meditation, may offer psychological, cognitive, and physiological benefits to both cognitively impaired adults and their caregivers, which in turn could have important implications for physical and mental health, emotional well-being, and cognitive function in both populations.

Strengths of the study include the community-based design, the inclusion of both cognitively impaired patients and their caregivers, and the high retention and compliance of participants. However, limitations of this pilot study are several. The sample size was small, limiting power and generalizability. The study lacked a control group, raising the possibility that our findings could be in part explained by a placebo effect. However, adjustment for treatment expectancy did not attenuate the observed improvements, suggesting that expectation of benefit did not account for the observed improvements. Participants were relatively well educated, most were retired, and all were non-Hispanic white, again limiting generalizability to other ethnic and socioeconomic groups. Our study sample comprised communityliving dyads who were willing and able to participate in a meditation trial and thus are likely not representative of all cognitively impaired adults and their caregivers. The study was relatively short term and did not include a follow-up component, so persistence of benefits is unknown.

4.1. Conclusions. Findings of this exploratory trial suggest that a simple meditation program may offer an acceptable and effective intervention for reducing perceived stress and blood pressure, and improving certain domains of sleep, mood, and memory in adults with mild cognitive impairment or early stage Alzheimer's disease and their caregivers. These preliminary findings warrant confirmation in larger, controlled trials and in ethnically and socioeconomically diverse populations.

\section{References}

[1] S. Gauthier, "Should we encourage the use of high-dose vitamin $\mathrm{E}$ in persons with memory complaints as a preventive strategy against Alzheimer's disease?" Journal of Psychiatry and Neuroscience, vol. 25, no. 4, p. 394, 2000.

[2] National Center for Health Statistics, "Deaths and mortality," 2004, http://www.cdc.gov/nchs/fastats/deaths.htm.

[3] Report on Alzheimer's Disease, Alzheimer's Association, Chicago, Ill, usa, 2009.

[4] D. S. Khalsa, "Mindfulness effects on caregiver stress: should we expect more?" Journal of Alternative and Complementary Medicine, vol. 16, no. 10, pp. 1025-1026, 2010.

[5] R. G. Logsdon and L. Teri, "The pleasant events schedule-AD: psychometric properties and relationship to depression and cognition in Alzheimer's disease patients," Gerontologist, vol. 37, no. 1, pp. 40-45, 1997.

[6] L. Teri, "Behavior and caregiver burden: behavioral problems in patients with Alzheimer disease and its association with caregiver distress," Alzheimer Disease and Associated Disorders, vol. 11, no. 4, pp. S35-S38, 1997.

[7] Y. F. Y. Lu and J. E. Haase, "Experience and perspectives of caregivers of spouse with mild cognitive impairment," Current Alzheimer Research, vol. 6, no. 4, pp. 384-391, 2009.

[8] P. B. Rosenberg, M. M. Mielke, B. Appleby, E. Oh, J. M. Leoutsakos, and C. G. Lyketsos, "Neuropsychiatric symptoms in MCI subtypes: the importance of executive dysfunction," International Journal of Geriatric Psychiatry, vol. 26, no. 4, pp. 364-372, 2011.

[9] S.-H. Ryu and K.-J. Lee, "Neuropsychiatric symptoms in patients with mild cognitive impairment and mild Alzheimer's disease in the community-dwelling elderly in Korea," Alzheimer's and Dementia, vol. 4, no. 4, supplement 1, p. T450, 2008.

[10] A. Rongve, B. F. Boeve, and D. Aarsland, "Frequency and correlates of caregiver-reported sleep disturbances in a sample of persons with early dementia," Journal of the American Geriatrics Society, vol. 58, no. 3, pp. 480-486, 2010.

[11] S. Beaulieu-Bonneau and C. Hudon, "Sleep disturbances in older adults with mild cognitive impairment," International Psychogeriatrics, vol. 21, no. 4, pp. 654-666, 2009.

[12] Y. Winter, A. Korchounov, T. V. Zhukova, and N. E. Bertschi, "Depression in elderly patients with Alzheimer dementia or vascular dementia and its influence on their quality of life," Journal of Neurosciences in Rural Practice, vol. 2, no. 1, pp. 2732, 2011.

[13] F. Panza, V. Frisardi, C. Capurso et al., "Late-Life depression, mild cognitive impairment, and dementia: possible continuum?" American Journal of Geriatric Psychiatry, vol. 18, no. 2, pp. 98-116, 2010. 
[14] L. W. Caswell, P. P. Vitaliano, K. L. Croyle, J. M. Scanlan, J. Zhang, and A. Daruwala, "Negative associations of chronic stress and cognitive performance in older adult spouse caregivers," Experimental Aging Research, vol. 29, no. 3, pp. 303 318, 2003.

[15] S. M. McCurry, L. E. Gibbons, R. G. Logsdon, M. V. Vitiello, and L. Teri, "Insomnia in caregivers of persons with dementia: who is at risk and what can be done about it?" Sleep Medicine Clinics, vol. 4, no. 4, pp. 519-526, 2009.

[16] C. Eisdorfer, "Caregiving: an emerging risk factor for emotional and physical pathology," Bulletin of the Menninger Clinic, vol. 55, no. 2, pp. 238-247, 1991.

[17] S. M. McCurry, R. G. Logsdon, L. Teri, and M. V. Vitiello, "Sleep disturbances in caregivers of persons with dementia: contributing factors and treatment implications," Sleep Medicine Reviews, vol. 11, no. 2, pp. 143-153, 2007.

[18] G. Tremont, "Family caregiving in dementia," Medicine and health, Rhode Island, vol. 94, no. 2, pp. 36-38, 2011.

[19] J. M. Bruce, M. McQuiggan, V. Williams, H. Westervelt, and G. Tremont, "Burden among spousal and child caregivers of patients with mild cognitive impairment," Dementia and Geriatric Cognitive Disorders, vol. 25, no. 4, pp. 385-390, 2008.

[20] Y. F. Y. Lu, M. G. Austrom, S. M. Perkins et al., "Depressed mood in informal caregivers of individuals with mild cognitive impairment," American Journal of Alzheimer's Disease and other Dementias, vol. 22, no. 4, pp. 273-285, 2007.

[21] K. A. Ryan, A. Weldon, N. M. Huby et al., "Caregiver support service needs for patients with mild cognitive impairment and Alzheimer disease," Alzheimer Disease and Associated Disorders, vol. 24, no. 2, pp. 171-176, 2010.

[22] S. M. McCurry, M. V. Vitiello, L. E. Gibbons, R. G. Logsdon, and L. Teri, "Factors associated with caregiver reports of sleep disturbances in persons with dementia," American Journal of Geriatric Psychiatry, vol. 14, no. 2, pp. 112-120, 2006.

[23] R. F. Allegri, D. Sarasola, C. M. Serrano et al., "Neuropsychiatric symptoms as a predictor of caregiver burden in Alzheimer's disease," Neuropsychiatric Disease and Treatment, vol. 2, no. 1, pp. 105-110, 2006.

[24] D. R. Lee and A. J. Thomas, "Sleep in dementia and caregiving-assessment and treatment implications: a review," International Psychogeriatrics, vol. 23, no. 2, pp. 190-201, 2011.

[25] B. F. Boeve, "Update on the diagnosis and management of sleep disturbances in dementia," Sleep Medicine Clinics, vol. 3, no. 3, pp. 347-360, 2008.

[26] R. Bonadonna, "Meditation's impact on chronic illness," Holistic Nursing Practice, vol. 17, no. 6, pp. 309-319, 2003.

[27] K. E. Innes, C. Bourguignon, and A. G. Taylor, "Risk indices associated with the insulin resistance syndrome, cardiovascular disease, and possible protection with yoga: a systematic review," Journal of the American Board of Family Practice, vol. 18, no. 6, pp. 491-519, 2005.

[28] R. H. Schneider, K. G. Walton, J. W. Salerno, and S. I. Nidich, "Cardiovascular disease prevention and health promotion with the transcendental meditation program and Maharishi consciousness-based health care," Ethnicity and Disease, vol. 16, no. 3, supplement 4, pp. 15-26, 2006.

[29] K. E. Innes, T. K. Selfe, and A. Vishnu, "Mind-body therapies for menopausal symptoms: a systematic review," Maturitas, vol. 66, no. 2, pp. 135-149, 2010.

[30] T. K. Selfe and K. E. Innes, "Mind-body therapies and osteoarthritis of the knee," Current Rheumatology Reviews, vol. 5, no. 4, pp. 204-211, 2009.

[31] L. C. Waelde, L. Thompson, and D. Gallagher-Thompson, "A pilot study of a yoga and meditation intervention for dementia caregiver stress," Journal of Clinical Psychology, vol. 60, no. 6, pp. 677-687, 2004.

[32] L. E. Carlson and S. N. Garland, "Impact of Mindfulness-Based Stress Reduction (MBSR) on sleep, mood, stress and fatigue symptoms in cancer outpatients," International Journal of Behavioral Medicine, vol. 12, no. 4, pp. 278-285, 2005.

[33] J. D. Lane, J. E. Seskevich, and C. F. Pieper, "Brief meditation training can improve perceived stress and negative mood," Alternative Therapies in Health and Medicine, vol. 13, no. 1, pp. 38-44, 2007.

[34] R. Jayadevappa, J. C. Johnson, B. S. Bloom et al., "Effectiveness of transcendental meditation on functional capacity and quality of life of African Americans with congestive heart failure: a randomized control study," Ethnicity and Disease, vol. 17, no. 1, pp. 72-77, 2007, erratum appears in Ethnicity and Disease vol. 17, no. 3, page 595 .

[35] V. K. Sharma, S. Das, S. Mondal, U. Goswami, and A. Gandhi, "Effect of Sahaj Yoga on neuro-cognitive functions in patients suffering from major depression," Indian Journal of Physiology and Pharmacology, vol. 50, no. 4, pp. 375-383, 2006.

[36] J. P. Manikonda, S. Störk, S. Tögel et al., "Contemplative meditation reduces ambulatory blood pressure and stress-induced hypertension: a randomized pilot trial," Journal of Human Hypertension, vol. 22, no. 2, pp. 138-140, 2008.

[37] L. McBee, Mindfulness-Based Elder Care. A CAM Model for Frail Elders and Their Caregivers, Springer Publishing Company, New York, NY, USA, 2008.

[38] M. S. Lantz, E. N. Buchalter, and L. McBee, "The wellness group: a novel intervention for coping with disruptive behavior in elderly nursing home residents," Gerontologist, vol. 37, no. 4, pp. 551-556, 1997.

[39] A. B. Newberg, N. Wintering, D. S. Khalsa, H. Roggenkamp, and M. R. Waldman, "Meditation effects on cognitive function and cerebral blood flow in subjects with memory loss: a preliminary study," Journal of Alzheimer's Disease, vol. 20, no. 2, pp. 517-526, 2010.

[40] S. Cohen, T. Kamarck, and R. Mermelstein, "A global measure of perceived stress," Journal of Health and Social Behavior, vol. 24, no. 4, pp. 385-396, 1983.

[41] B. G. Berger and R. W. Motl, "Exercise and mood: a selective review and synthesis of research employing the profile of mood states," Journal of Applied Sport Psychology, vol. 12, no. 1, pp. 69-92, 2000.

[42] D. Watson, L. A. Clark, and A. Tellegen, "Development and validation of brief measures of positive and negative affect: the PANAS scales," Journal of Personality and Social Psychology, vol. 54, no. 6, pp. 1063-1070, 1988.

[43] P. Bartone, R. Ursano, K. Wright, and L. Ingraham, "The impact of a military air disaster on the health of assistance workers: a prospective study," Journal of Nervous and Mental Disease, vol. 177, no. 6, pp. 317-328, 1989.

[44] K. A. Lee, "Self-reported sleep disturbances in employed women," Sleep, vol. 15, no. 6, pp. 493-498, 1992.

[45] K. Neff, "Development and validation of a scale to measure self-compassion," Self and Identity, vol. 2, pp. 223-250, 2003.

[46] M. J. Gilewski, E. M. Zelinski, and K. W. Schaie, "The Memory Functioning Questionnaire for assessment of memory complaints in adulthood and old age," Psychology and Aging, vol. 5, no. 4, pp. 482-490, 1990.

[47] M. DiBenedetto, K. E. Innes, A. G. Taylor et al., "Effect of a gentle iyengar yoga program on gait in the elderly: 
an exploratory study," Archives of Physical Medicine and Rehabilitation, vol. 86, no. 9, pp. 1830-1837, 2005.

[48] D. S. Khalsa, D. Amen, C. Hanks, N. Money, and A. Newberg, "Cerebral blood flow changes during chanting meditation," Nuclear Medicine Communications, vol. 30, no. 12, pp. 956961, 2009.

[49] B. S. Oken, I. Fonareva, M. Haas et al., "Pilot controlled trial of mindfulness meditation and education for dementia caregivers," Journal of Alternative and Complementary Medicine, vol. 16, no. 10, pp. 1031-1038, 2010.

[50] C. Franco, M. D.M. Sola, and E. Justo, "Reducing psychological discomfort and overload in Alzheimer's family caregivers through a mindfulness meditation program," Revista Espanola de Geriatria y Gerontologia, vol. 45, no. 5, pp. 252-258, 2010 (Spanish).

[51] G. P. Epstein-Lubow, I. W. Miller, and L. McBee, "Mindfulness training for caregivers," Psychiatric Services, vol. 57, no. 3, p. 421, 2006.

[52] R. Schulz and L. M. Martire, "Family caregiving of persons with dementia: prevalence, health effects, and support strategies," American Journal of Geriatric Psychiatry, vol. 12, no. 3, pp. 240-249, 2004.

[53] M. E. Alspaugh, M. A. Stephens, A. L. Townsend, S. H. Zarit, and R. Greene, "Longitudinal patterns of risk for depression in dementia caregivers: objective and subjective primary stress as predictors," Psychology and Aging, vol. 14, no. 1, pp. 34-43, 1999.

[54] B. Lovell and M. A. Wetherell, "The cost of caregiving: endocrine and immune implications in elderly and non elderly caregivers," Neuroscience and Biobehavioral Reviews, vol. 35, no. 6, pp. 1342-1352, 2011.

[55] J. E. Dimsdale, "Psychological stress and cardiovascular disease," Journal of the American College of Cardiology, vol. 51, no. 13, pp. 1237-1246, 2008.

[56] P. P. Vitaliano, J. M. Scanlan, J. Zhang, M. V. Savage, I. B. Hirsch, and I. C. Siegler, "A path model of chronic stress, the metabolic syndrome, and coronary heart disease," Psychosomatic Medicine, vol. 64, no. 3, pp. 418-435, 2002.

[57] R. S. Wilson, S. E. Arnold, J. A. Schneider, Y. Li, and D. A. Bennett, "Chronic distress, age-related neuropathology, and latelife dementia," Psychosomatic Medicine, vol. 69, no. 1, pp. 4753, 2007.

[58] B. S. McEwen, "Sex, stress and the hippocampus: allostasis, allostatic load and the aging process," Neurobiology of Aging, vol. 23, no. 5, pp. 921-939, 2002.

[59] K. E. Innes, H. K. Vincent, and A. G. Taylor, "Chronic stress and insulin resistance-related indices of cardiovascular disease risk, part I: neurophysiological responses and pathological sequelae," Alternative Therapies in Health and Medicine, vol. 13, no. 4, pp. 46-52, 2007.

[60] J. E. Kang, J. R. Cirrito, H. Dong, J. G. Csernansky, and D. M. Holtzman, "Acute stress increases interstitial fluid amyloid- $\beta$ via corticotropin-releasing factor and neuronal activity," Proceedings of the National Academy of Sciences of the United States of America, vol. 104, no. 25, pp. 10673-10678, 2007.

[61] D. M. Clarke and K. C. Currie, "Depression, anxiety and their relationship with chronic diseases: a review of the epidemiology, risk and treatment evidence," Medical Journal of Australia, vol. 190, no. 7, pp. S54-S60, 2009.

[62] B. E. Cohen, P. Panguluri, B. Na, and M. A. Whooley, "Psychological risk factors and the metabolic syndrome in patients with coronary heart disease: findings from the Heart and Soul Study," Psychiatry Research, vol. 175, no. 1-2, pp. 133-137, 2010.

[63] F. S. Luppino, L. M. de Wit, P. F. Bouvy et al., "Overweight, obesity, and depression: a systematic review and meta-analysis of longitudinal studies," Archives of General Psychiatry, vol. 67, no. 3, pp. 220-229, 2010.

[64] T. H. Valimaki, K. M. Vehviläinen-Julkunen, A. M. Pietilä, and T. A. Pirttilä, "Caregiver depression is associated with a low sense of coherence and health-related quality of life," Aging and Mental Health, vol. 13, no. 6, pp. 799-807, 2009.

[65] B. E. Leonard, "Inflammation, depression and dementia: are they connected?" Neurochemical Research, vol. 32, no. 10, pp. 1749-1756, 2007.

[66] B. S. McEwen, "Physiology and neurobiology of stress and adaptation: central role of the brain," Physiological Reviews, vol. 87, no. 3, pp. 873-904, 2007.

[67] M. J. Peterson and R. M. Benca, "Sleep in mood disorders," Sleep Medicine Clinics, vol. 3, no. 2, pp. 231-249, 2008.

[68] B. S. McEwen, "Sleep deprivation as a neurobiologic and physiologic stressor: allostasis and allostatic load," Metabolism: Clinical and Experimental, vol. 55, no. 10, supplement 2, pp. S20S23, 2006.

[69] K. E. Innes, T. K. Selfe, and A. G. Taylor, "Menopause, the metabolic syndrome, and mind-body therapies," Menopause, vol. 15, no. 5, pp. 1005-1013, 2008.

[70] M. A. Miller and F. P. Cappuccio, "Inflammation, sleep, obesity and cardiovascular disease," Current Vascular Pharmacology, vol. 5, no. 2, pp. 93-102, 2007.

[71] E. C. Suarez, "Self-reported symptoms of sleep disturbance and inflammation, coagulation, insulin resistance and psychosocial distress: evidence for gender disparity," Brain, Behavior, and Immunity, vol. 22, no. 6, pp. 960-968, 2008.

[72] M. I. Trenell, N. S. Marshall, and N. L. Rogers, "Sleep and metabolic control: waking to a problem?" Clinical and Experimental Pharmacology and Physiology, vol. 34, no. 1-2, pp. 1-9, 2007.

[73] D. Foley, S. Ancoli-Israel, P. Britz, and J. Walsh, "Sleep disturbances and chronic disease in older adults: results of the 2003 National Sleep Foundation Sleep in America Survey," Journal of Psychosomatic Research, vol. 56, no. 5, pp. 497-502, 2004.

[74] M. V. Rainforth, R. H. Schneider, S. I. Nidich, C. GaylordKing, J. W. Salerno, and J. W. Anderson, "Stress reduction programs in patients with elevated blood pressure: a systematic review and meta-analysis," Current Hypertension Reports, vol. 9, no. 6, pp. 520-528, 2007.

[75] J. W. Anderson, C. Liu, and R. J. Kryscio, "Blood pressure response to transcendental meditation: a meta-analysis," American Journal of Hypertension, vol. 21, no. 3, pp. 310-316, 2008.

[76] W. S. Shaw, T. L. Patterson, M. G. Ziegler, J. E. Dimsdale, S. J. Semple, and I. Grant, "Accelerated risk of hypertensive blood pressure recordings among Alzheimer caregivers," Journal of Psychosomatic Research, vol. 46, no. 3, pp. 215-227, 1999.

[77] R. von Känel, B. T. Mausbach, T. L. Patterson et al., "Increased Framingham coronary heart disease risk score in dementia caregivers relative to non-caregiving controls," Gerontology, vol. 54, no. 3, pp. 131-137, 2008.

[78] M. Kivipelto, T. Ngandu, L. Fratiglioni et al., "Obesity and vascular risk factors at midlife and the risk of dementia and Alzheimer disease," Archives of Neurology, vol. 62, no. 10, pp. 1556-1560, 2005. 
[79] I. Skoog and D. Gustafson, "Update on hypertension and Alzheimer's disease," Neurological Research, vol. 28, no. 6, pp. 605-611, 2006.

[80] L. Kilander, H. Nyman, M. Boberg, L. Hansson, and H. Lithell, "Hypertension is related to cognitive impairment: a 20-year follow-up of 999 men," Hypertension, vol. 31, no. 3, pp. 780786, 1998. 


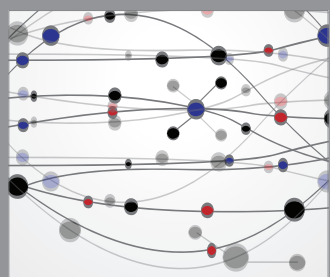

The Scientific World Journal
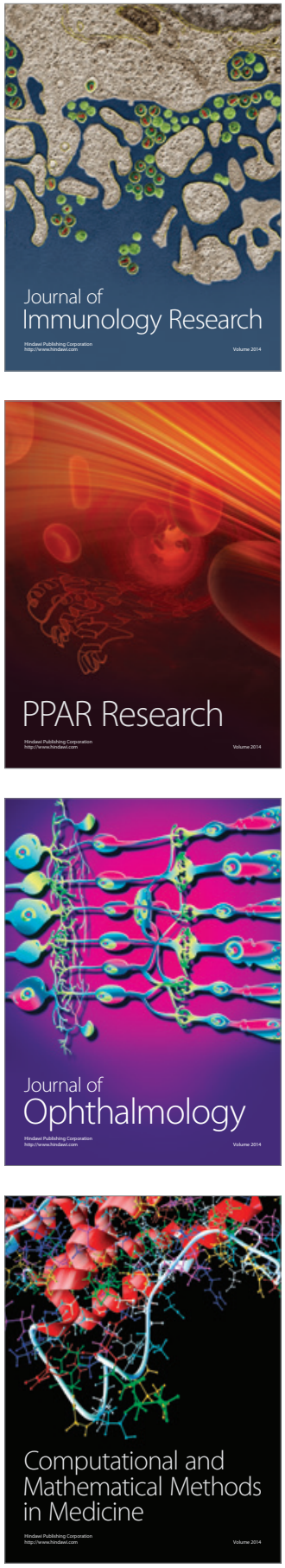

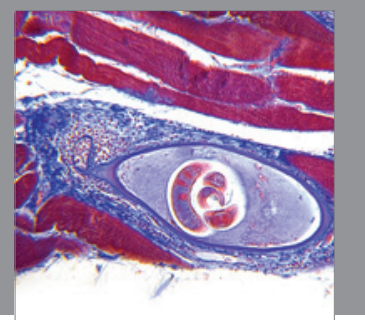

Gastroenterology

Research and Practice
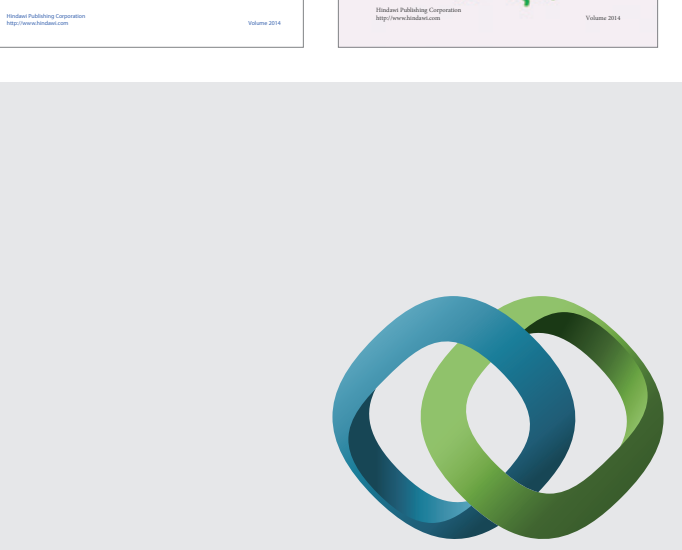

\section{Hindawi}

Submit your manuscripts at

http://www.hindawi.com
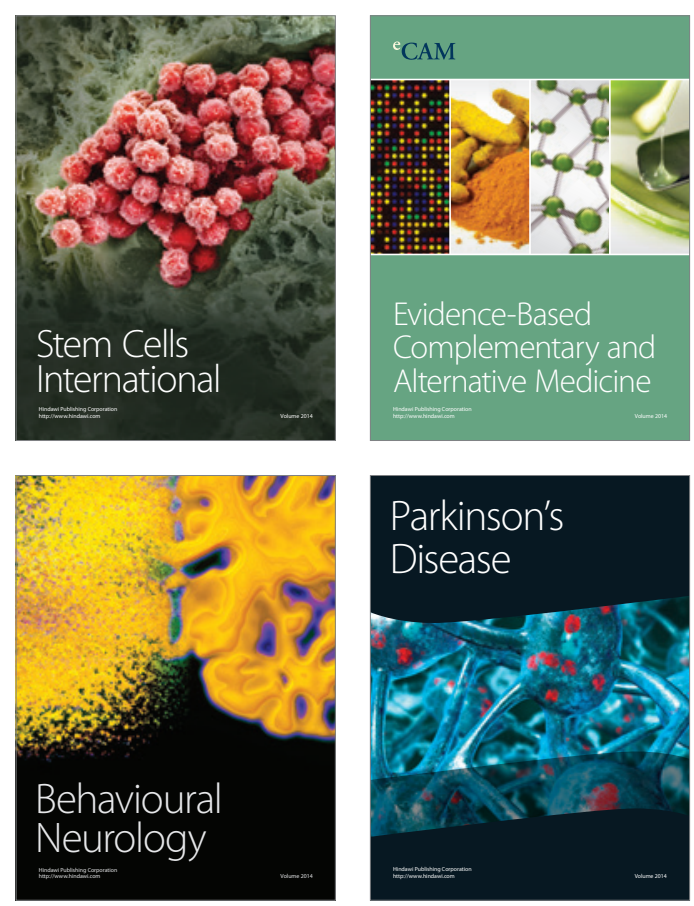

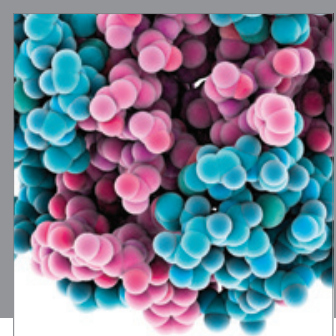

Journal of
Diabetes Research

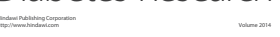

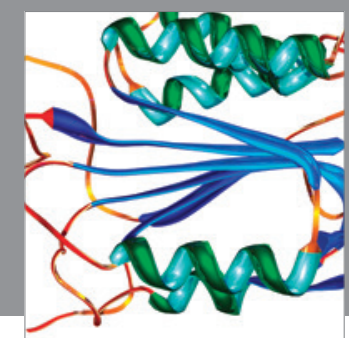

Disease Markers
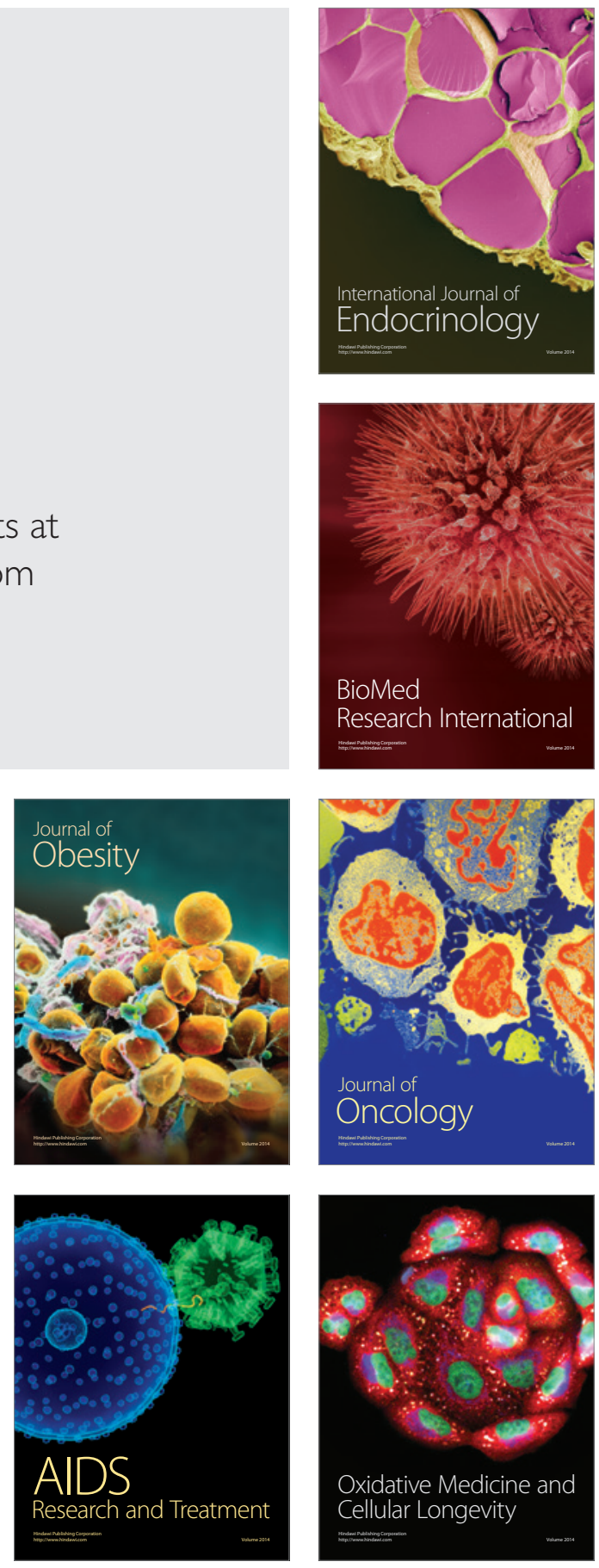